\title{
Impactos ambientais decorrentes do uso e ocupação desordenada do espaço urbano: um estudo de caso da cidade de Baixio/CE
}

\section{Environmental impacts arising from the use and occupancy of urban space disorderly: a case study of town of Baixio/CE}

\author{
Diêgo Lima Crispim ${ }^{1}$, Sanduel Oliveira de Andrade ${ }^{2}$, José Alison Dias de Meneses $^{3}$; Alan Del Carlos Gomes Chaves ${ }^{4}$ e Maria \\ da Glória Borba Borges 5
}

\begin{abstract}
RESUMO - O acelerado processo de urbanização é um dos fatores determinantes do novo padrão da constituição da atual sociedade brasileira, ligado a um conjunto de transformações sociais, econômicas, políticas e demográficas enfrentado após da década de 1950. Diante do exposto, o presente trabalho tem por finalidade analisar os impactos ambientais ocasionado pela ocupação desordenada, gerando uma maior produção de efluentes domésticos na cidade de Baixio-CE. Durante a pesquisa foi possível observar que os impactos são advindos da questão habitacional. Fenômeno este, agravado pelo fato da Constituição não obrigar que haja Plano Diretor para municípios com população inferior a vinte mil habitantes. Sendo que, é de responsabilidade do município legislar sobre questões relativas a problemas locais. Foi constatado grande quantidade de efluentes domésticos sendo lançado a céu aberto, sem seu devido tratamento, ocasionando sérios danos ambientais, contaminando da água e do solo, podendo ser uma importante forma de transmissão de doenças para a população exposta.
\end{abstract}

PALAVRAS-CHAVE: Saneamento básico, Saúde, Qualidade de vida.

ABSTRACT - The accelerated process of urbanization is one of the determinants the new model of the constitution of the current Brazilian society, connected to a set of social, economic, political and demographic changes faced after the 1950s. Considering the above factors, this study aims to analyze the environmental impacts caused by the disorderly occupation, causing more production of domestic sewage in the town of Baixio-CE. During the research it was observed that the impacts are arising from the housing issue. This phenomenon, aggravated by fact that the Constitution does not require that there Master Plan for counties with less than twenty thousand inhabitants. Being that it is the responsibility of the county to legislate on matters relating to local problems. Large amount of domestic sewage being released was found the open air without their proper treatment, causing serious environmental damage, contaminating the water and soil, and can be an important way of transmitting diseases to the exposed population.

KEY WORDS: Sanitation, health, quality of life.

\footnotetext{
*Autor para correspondência

Recebido em 12/01/2014 e aceito em 20/11/2014

${ }^{1}$ Engenheiro Ambiental, UFCG. Especializando em Educação Ambiental e Geografia do Semiárido, IFRN. Mestrando em Sistemas Agroindustriais, UFCG.

E-mail: diegolc_85@hotmail.com

${ }^{2}$ Engenheiro Agrônomo, UFCG. Especialista em Geoprocessamento, FIP. Especializando em Educação Ambiental e Geografia do Semiárido, IFRN.

Mestrando em Sistemas Agroindustriais, UFCG. E-mail: sanduelandrade@hotmail.com

${ }^{3}$ Graduando em Direito, FAFIC. E-mail: alisonbaixio@ hotmail.com

${ }^{4}$ Licenciatura Plena em Geografia, FIP. Especialista em Educação Ambiental e Sustentabilidade, UFCG. Mestre em Sistemas Agroindustriais, UFCG,

Pombal-PB, e-mail: alandcgc@hotmail.com

${ }^{5}$ Mestranda do PPGSA/CCTA/UFCG Mestre em Sistemas Agroindustriais, UFCG, Pombal-PB, e-mail: borbagloria@hotmail.com
} 


\section{INTRODUÇÃO}

O Brasil passou nas últimas seis décadas por um processo intenso e descontrolado de urbanização, provocado em grande medida pela industrialização e pelo êxodo rural. Contudo, nas cidades de pequeno porte, esse fenômeno é resultante especificamente da falta de emprego e da ausência de serviços públicos essenciais.

Esses fenômenos geraram e tem gerado distorções no uso do espaço urbano, de forma a ensejar o aparecimento de aglomerações sem as condições mínimas de qualidade de vida aos habitantes desses locais, da mesma forma colaborando para a modificação da paisagem e espaço naturais.

Além dos problemas ambientais, o modelo de urbanização brasileiro vem sendo caracterizado pela exclusão social, territorial e pela discriminação do espaço desde o início, e principalmente nas últimas décadas (MELO et al., 2006).

O processo de urbanização, por ter caráter coletivo, enseja a responsabilidade do Estado como agente regulador, fiscalizador e principalmente planejador. Esse último aspecto ganhou relevância na nova ordem constitucional, pois está previsto na Carta Magna que a Administração Pública é responsável pela política urbana.

Pela importância assumida no cenário social do país, o tema urbanístico tem provocado muitos debates e estudos dirigidos à resolução dos graves problemas enfrentados pelas cidades, oriundos da falta ou de um gerenciamento inadequado do planejamento.

Inserido nessa temática, o presente trabalho visa analisar os impactos ao meio ambiente ocasionado pela ocupação desordenada que tem gerado uma maior produção e destinação imprópria de efluentes domésticos na cidade.

Por ser um tema refletido por todas as entidades representativas da sociedade e que tem provocado desarranjos na estrutura das cidades, trazendo prejuízos das mais variadas ordens, analisar e apresentar dados e informações concernentes a problemática é uma maneira de contribuir para uma cidade que possibilite o pleno desenvolvimento do potencial humano.

\section{MATERIAL E MÉTODOS}

\section{Caracterização da área de estudo}

O município de Baixio está situado na região sudeste do Estado do Ceará, na mesorregião do centro-sul Cearense, e na microrregião de Lavras da Mangabeira, entre as coordenadas geográficas $38^{\circ} 43^{\prime} 01^{\prime}$ ' longitude oeste e $6^{\circ} 43^{\prime}$ 48 " de latitude sul. Limita-se ao norte com o município de Umari; a leste com o Estado da Paraíba; ao sul com o município de Ipaumirim e a oeste com o município de Lavras da Mangabeira.

O município possui uma área total de, aproximadamente, $146,44 \mathrm{~km}^{2}$, segundo dados do Instituto Brasileiro de Geografia e Estatística (IBGE, 2010) e do Instituto de Pesquisa e Estratégia Econômica do Ceará (IPECE, 2013).
A sede municipal se situa a uma altitude de 269,0 metros e a população estimada no município para o ano de 2013 é de 6.175 habitantes (IBGE, 2010).

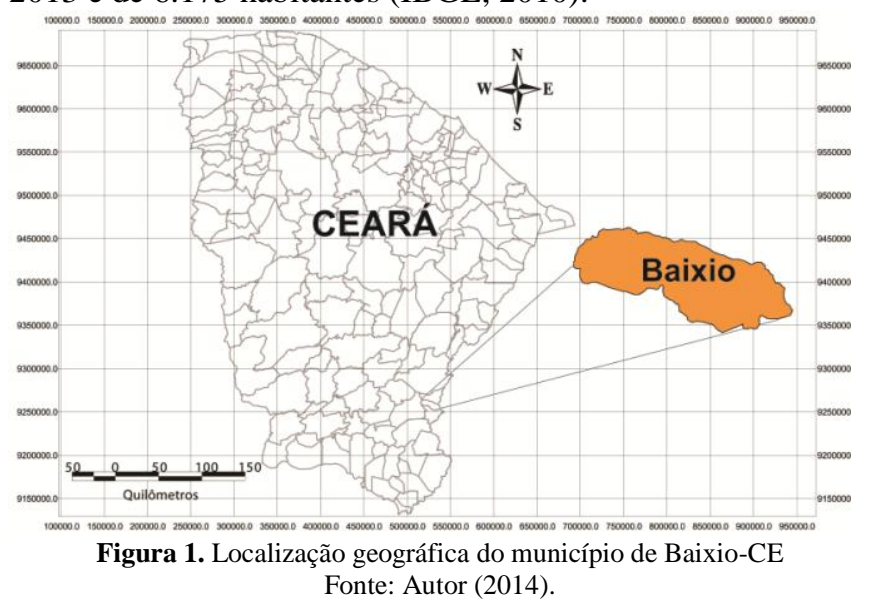

\section{Aspectos climáticos}

O município de Baixio apresenta um clima do tipo tropical quente semiárido (IPECE; FUNCEME, 2013). A temperatura média $\left({ }^{\circ} \mathrm{C}\right)$ varia entre 26 e $28{ }^{\circ} \mathrm{C}$. Em relação ao dado do índice de pluviosidade anual é estimado em 741,5 $\mathrm{mm}$.

\section{Componentes ambientais}

A vegetação é do tipo Caatinga Arbustiva Densa e Floresta Caducifólia Espinhosa. As espécies predominantes da Caatinga arbustiva densa são a Amburana cearensis, Spondias tuberosa, Aspidosperma pyrifolium, em uma matriz arbustiva de Caesalpinia spp., Mimosa spp., Jatropha spp., e Acacia spp. (LEAL et al., 2003). A Floresta Caducifólia Espinhosa, formação vegetal, típica do nordeste brasileiro, definida como: um conjunto de arbustos e de árvores espontâneas, denso, baixo, de aspecto seco, de folhas pequenas, caducas no verão com raízes penetrantes e desenvolvidas [plantas xerófilas] (KAZMIERCZAK et al.,1996).

Os solos são, segundo a IPECE (2013) e EMBRAPA (2013), do tipo pouco profundo, constituídos de:

- Luvissolos: são solos rasos a pouco profundos, com horizonte B textural de cores vivas e argila de atividade alta. Apresentando-se moderadamente ácidos a neutros, com elevada saturação por bases. Apresentam frequentemente revestimento pedregoso na superfície ou na massa do solo e são altamente susceptíveis aos processos erosivos.

- Argissolos: apresenta um evidente incremento no teor de argila do horizonte superficial para o horizonte B. São de profundidade variável, desde forte a imperfeitamente. São forte a moderadamente ácidos, com saturação por bases alta ou baixa, drenados, de cores avermelhadas ou amareladas.

- Neossolos: solos constituídos por material mineral, ou por material orgânico, rasos, com menos de 20 cm de espessura. 


\section{A pesquisa}

Trata de um estudo de caso que abrange o crescimento urbano desordenado do Baixio - CE, com foco na ausência de coleta e tratamento de esgoto sanitário.

\section{Procedimentos metodológicos}

A pesquisa realizada foi de natureza qualitativa onde o ambiente em estudo foi a fonte direta para coleta de dados. Quanto ao tipo de pesquisa foram adotados os métodos descritivo e explicativa. Para abordagem da problemática utilizou-se a observação direta intensiva, pelo uso de fotografias; pesquisa em livros, internet, documentos públicos, periódicos e legislação pertinente.

\section{RESULTADOS E DISCUSSÃO}

As informações obtidas no decorrer do estudo sobre os impactos ambientais, consequente do uso e ocupação desordenada do solo, na cidade de Baixio - CE, mostram que na área em estudo, há inúmeros problemas advindos da questão habitacional. Fica claro que a falta de uma política urbana, nos termos do art. 182 da Carta Maior, preconizando como objetivo o pleno desenvolvimento das funções sociais da cidade e garantindo o bem-estar dos cidadãos está intimamente relacionado com essa questão.

Outro ponto que dificulta o acompanhamento do crescimento urbano na cidade é que a Constituição não obriga que haja Plano Diretor para municípios com população inferior a vinte mil habitantes, conforme reza o art. $182, \S$ 1.: "O plano diretor, aprovado pela Câmara Municipal, obrigatório para cidades com mais de vinte mil habitantes, é o instrumento básico da política de desenvolvimento e de expansão urbana".

Regulamentando o art. 182 da Constituição, foi criada a Lei 10.257, conhecida como Estatuto da Cidade, que consoante Andrade (2010), "estabelecendo as bases da política urbana com o objetivo de assegurar uma ocupação e exploração racional do solo e construções, de modo que a propriedade urbana possa cumprir sua função social".

Não obstante as cidades com menos de vinte mil habitantes não estarem obrigadas a fazerem o plano diretor, a Carta Política no art. 30, I, diz ser de competência dos municípios legislar sobre assuntos de interesse local. Para Lenza (2012, p. 448), "interesse local diz respeito às peculiaridades e necessidades ínsitas à localidade". No caso do Baixio, está parado na Câmara Municipal o Projeto de Lei $\mathrm{n}^{\circ}$ 008/2013, Código de Posturas do Município, que trata da ocupação e uso do solo urbano.

Segundo o IBGE (2000), o crescimento urbano das cidades na sua maioria não consegue acompanhar o acesso aos serviços de saneamento básico, causando situações desconfortáveis a seus habitantes. O município de Baixio-CE não é uma exceção no país, durante a realização do estudo foram observadas diversas situações que ratifica tal cenário, como por exemplo, o lançamento de esgoto doméstico a céu aberto, como pode ser observado na figura 2. No Brasil, $11 \%$ dos domicílios têm esgoto a céu aberto no entorno da residência (IBGE, 2010). A Lei $\mathrm{n}^{\circ} 11.445 / 07$, que estabelece diretrizes nacionais para o saneamento básico, conceitua-o, incluindo nele esgotamento sanitário, nos seguintes termos:

Art. $3^{\circ}$ Para os efeitos desta Lei, considera-se:

I - saneamento básico: conjunto de serviços, infraestruturas e instalações operacionais de:

[...]

b) esgotamento sanitário: constituído pelas atividades, infraestruturas e instalações operacionais de coleta, transporte, tratamento e disposição final adequados dos esgotos sanitários, desde as ligações prediais até o seu lançamento final no meio ambiente.

$[\ldots]$

É preceituado na Constituição que compete ao município prestar os serviços de interesse local, in verbis:

\section{Art. 30. Compete aos Municípios:}

[...]

V - organizar e prestar, diretamente ou sob regime de concessão ou permissão, os serviços públicos de interesse local, incluindo os de transporte coletivo, que tem caráter essencial;

[...]

O município sob análise deve prestar o serviço de esgotamento sanitário, pois como visto é de sua responsabilidade. $\mathrm{Na}$ lei $11.445 / 07$, é permitida a possibilidade de solução individual em matéria de esgotamento:

Art. 45. Ressalvadas as disposições em contrário das normas do titular, da entidade de regulação e de meio ambiente, toda edificação permanente urbana será conectada às redes públicas de abastecimento de água e de esgotamento sanitário disponíveis e sujeita ao pagamento das tarifas e de outros preços públicos decorrentes da conexão e do uso desses serviços.

$\S 1^{\text {o }} \mathrm{Na}$ ausência de redes públicas de saneamento básico, serão admitidas soluções individuais de abastecimento de água e de afastamento e destinação final dos esgotos sanitários, observadas as normas editadas pela entidade reguladora e pelos órgãos responsáveis pelas políticas ambiental, sanitária e de recursos hídricos.

$[\ldots]$

Essas ditas soluções individuais também encontram previsão no projeto de lei do Código de Postura do Município, que estabelece o uso de fossas e sumidouros coletivos ou individuais. E detalhando a parte final do parágrafo $1^{\circ}$ do art. 45 da Lei 11.445/07, o retrocitado Código estabelece as normas a serem seguidas na construção e manutenção das fossas e sumidouros: 
Art. 39. A construção de fossas deverá satisfazer a todos os requisitos sanitários, devendo atender ainda às seguintes exigências:

I. Não poderão ser adotadas as fossas negras, assim atendidas, aquelas que causem a poluição do lençol freático;

II. As fossas sépticas deverão ser construídas e mantidas obedecendo às prescrições da $\mathrm{ABNT}$;

III. As fossas de preferência deverão ser construídas na frente dos lotes distando no mínimo 15,00 m (quinze metros) de poços e não deverão causar direta ou indiretamente a poluição do solo;

IV. Não deverá haver perigo da fossa poluir água subterrânea que esteja em comunicação com fontes, poços ou águas de superfície, tais como rios, riachos, lagos e córregos;

V. Devem ser evitados o mau cheiro, proliferação de insetos e os aspectos desagradáveis à vista.

Art. 40. A limpeza das fossas deverá ser feita de modo a não causar poluição do ambiente, devendo as firmas particulares, que trabalhem nesse ramo, ter autorização especial da Administração Pública.
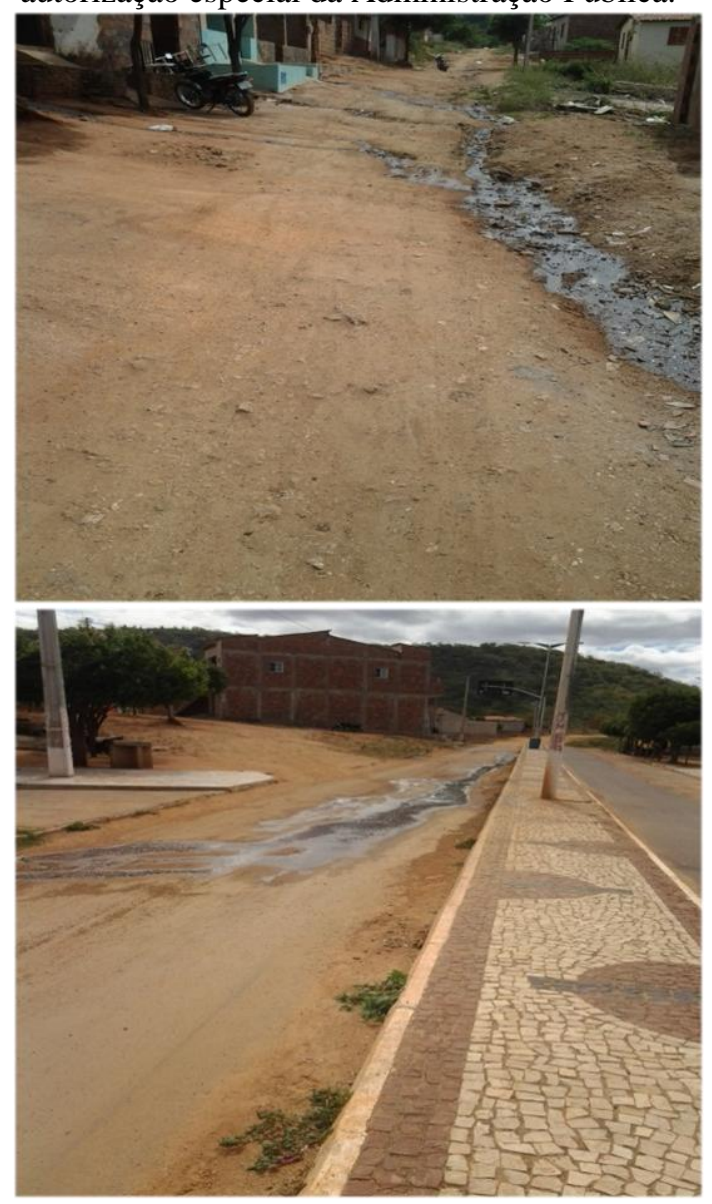

Figura 2. Lançamento de esgoto doméstico a céu

Os esgotos lançados a céu aberto constituem uma fonte contínua de transmissão de doenças de veiculação hídrica. No Brasil, lamentavelmente, $61,3 \%$ do esgoto produzido no país não recebe seu correto tratamento (SNIS, 2014).
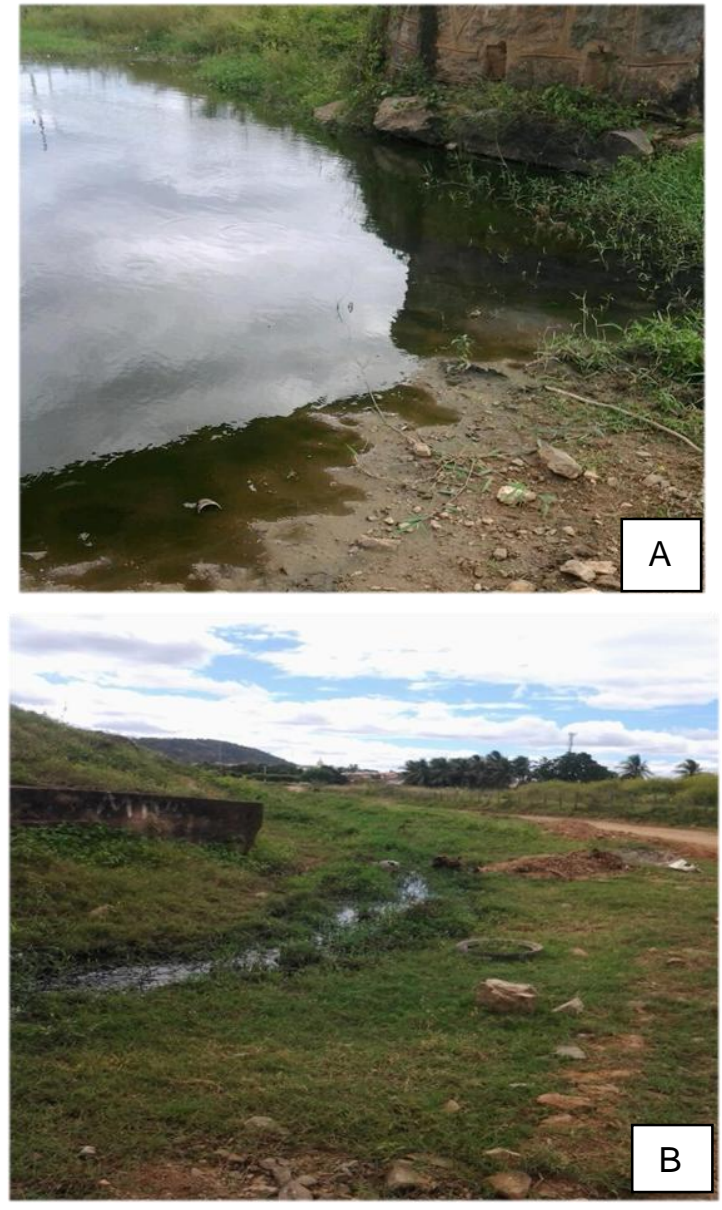

Figura 3. A. Acúmulo de esgoto sanitário no riacho Caio Prado. B. Vala de esgoto sanitário a céu aberto.

De acordo com Rocha (2009), um dos relevantes problemas que o Brasil encara, relativo à preservação e ao manejo dos recursos hídricos continentais e costeiros, diz respeito à contaminação por efluentes domésticos. É bastante disseminado no país, o pensamento de que os efluentes industriais são os grandes causadores da degradação dos recursos hídricos. Exceto para alguns bolsões de alta concentração industrial, os efluentes domésticos até então, são os principais responsáveis pela situação em que se encontram os nossos mananciais.

Segundo Costa (2008), uma considerável quantidade de cidades brasileiras não possui redes de coleta de esgotos, lançando seus efluentes em corpos d'água. O município de Baixio-CE é um exemplo desta situação, os efluentes sanitários são lançados in natura sem nenhum tipo de tratamento no riacho Caio Prado um afluente do rio Salgado, como pode ser verificado nas figuras $3 \mathrm{a}$ e $3 \mathrm{~b}$. O projeto de lei do Código de Postura do Município, trata dessa situação, estabelecendo:

Art. 24. Os resíduos líquidos ou sólidos, de origem doméstica, industrial ou de outra procedência, somente poderão ser lançados nas águas situadas no território do Município, interiores, superficiais ou subterrâneas, desde que não sejam considerados poluentes e tenha prévia anuência da Administração Municipal, ouvido o Conselho de Desenvolvimento 
Urbano e Meio Ambiente e o órgão estadual competente.

Em vista disso, deveria a Administração Pública monitorar ou proibir que os esgotos sejam despejados diretamente nesses riachos. O art. 25 do Código de Postura, diz que cabe a Administração Municipal fixar limites para o lançamento dos referidos esgotos nas águas.

A emissão dos efluentes pode resultar em diversos problemas socioambientais e em impactos significativos sobre a vida aquática e o ao meio natural. Crispim (2013) cita alguns tipos de problemas ocasionados pelo lançamento de efluentes sanitários em corpos d'água, tais como: poluição da água, diminuição da qualidade estética e paisagística, crescimento excessivo de algas, odores desagradáveis, depósito de lodo e doenças de veiculação hídrica.

Tabela 01. Impactos e as principais consequências no meio ambiente provocado por alguns fatores relacionados com o esgoto

\begin{tabular}{|c|c|}
\hline $\begin{array}{l}\text { Aspecto em } \\
\text { Foco }\end{array}$ & Consequências \\
\hline $\begin{array}{l}\text { Sólidos } \\
\text { suspensos e } \\
\text { dissolvidos }\end{array}$ & $\begin{array}{l}\text { Diminuição da vazão do rio e de } \\
\text { volumes de armazenamento } \\
\text { (Assoreamento), causando inundações; } \\
\text { Soterramento de animais e ovos de } \\
\text { peixes; } \\
\text { Aumento da turbidez da água, } \\
\text { provocando: redução da transparência } \\
\text { da água; diminuição da atividade } \\
\text { fotossintética; redução do oxigênio } \\
\text { dissolvido; impacto sobre a vida } \\
\text { aquática. }\end{array}$ \\
\hline Nutrientes & $\begin{array}{l}\text { Eutrofização da água; Proliferação de } \\
\text { algas e de vegetação aquática; } \\
\text { Prejuízos à recreação e navegação. }\end{array}$ \\
\hline $\begin{array}{l}\text { Presença dos } \\
\text { microrganismos } \\
\text { patogénicos }\end{array}$ & Transmissão de doenças ao homem. \\
\hline $\begin{array}{l}\text { Mudanças do } \\
\text { pH }\end{array}$ & Efeitos sobre a fauna e flora. \\
\hline $\begin{array}{l}\text { Compostos } \\
\text { tóxicos }\end{array}$ & $\begin{array}{l}\text { Danos à saúde humana; } \\
\text { Danos à vida aquática. }\end{array}$ \\
\hline Corantes & $\begin{array}{l}\text { Danos à vida aquática; } \\
\text { Prejuízos aos usos. }\end{array}$ \\
\hline $\begin{array}{l}\text { Substâncias } \\
\text { tenso-ativas }\end{array}$ & $\begin{array}{l}\text { Danos a fauna; } \\
\text { Geração de espumas. }\end{array}$ \\
\hline $\begin{array}{l}\text { Substâncias } \\
\text { radioativas }\end{array}$ & Danos à saúde humana e animal. \\
\hline
\end{tabular}

O esgoto doméstico ou efluente sanitário contém cerca de $99,9 \%$ de água e $0,1 \%$ de sólidos orgânicos e inorgânicos (MENDONÇA, 1990).

O esgoto de origem doméstica, do processamento de alimentos e de fontes industriais contém uma ampla gama de poluentes, inclusive de natureza orgânica (MANAHAN, 2013).

$\mathrm{Na}$ Tabela 3 apresenta os principais constituintes do esgoto e os inconvenientes resultante do lançamento de esgoto sanitários nos corpos d'água.
Tabela 2. Composição do esgoto doméstico

\begin{tabular}{|c|c|}
\hline Tipos de substâncias & Origem \\
\hline Sabões & Lavagem de louças e roupas \\
\hline Detergentes & Lavagem de louças e roupas \\
\hline Cloreto de sódio & Cozinhas e na urina humana \\
\hline Fosfatos & Detergentes e urina humana \\
\hline Sulfatos & Urina humana \\
\hline Carbonatos & Urina humana \\
\hline $\begin{array}{l}\text { Ureia, amoníaco e ácido } \\
\text { úrico }\end{array}$ & Urina humana \\
\hline Gorduras & Cozinhas e fezes humanas \\
\hline $\begin{array}{l}\text { Substâncias córneas, } \\
\text { ligamento da carne e fibras } \\
\text { vegetais não digeridas }\end{array}$ & Fezes humanas \\
\hline $\begin{array}{l}\text { Porções de amido } \\
\text { (glicogênio, glicose) e de } \\
\text { proteicos (aminoácidos, } \\
\text { proteínas, albumina) }\end{array}$ & Fezes humanas \\
\hline $\begin{array}{l}\text { Urobilina, pigmentos } \\
\text { hepáticos, etc. }\end{array}$ & Urina humana \\
\hline $\begin{array}{c}\text { Mucos, células de } \\
\text { descamação epitelial }\end{array}$ & Fezes humanas \\
\hline $\begin{array}{l}\text { Vermes, bactérias, vírus, } \\
\text { leveduras, etc. }\end{array}$ & Fezes humanas \\
\hline $\begin{array}{c}\text { Outros matérias e } \\
\text { substâncias: areia, } \\
\text { plásticos, cabelos, } \\
\text { sementes, fetos, madeira, }\end{array}$ & $\begin{array}{c}\text { Areia: infiltrações nas redes } \\
\text { de coleta, banho em cidades } \\
\text { litorâneas, parcela de águas } \\
\text { pluviais, etc. }\end{array}$ \\
\hline
\end{tabular}

absorventes femininos, etc.

Fonte: Adaptado a partir de Almeida Jr. (1985), Jordão e Pessoa (1995) e Pegoraro (s/d).

Tabela 3. Alguns dos principais constituintes do esgoto em um sistema de esgoto urbano

\begin{tabular}{c|c}
\hline Constituintes & Efeitos na água \\
\hline $\begin{array}{c}\text { Substâncias } \\
\text { de oxigemanda }\end{array}$ & Tóxicos à vida aquática \\
\hline $\begin{array}{c}\text { Orgânicos } \\
\text { refratários }\end{array}$ & $\begin{array}{c}\text { Causam doenças (possivelmente } \\
\text { câncer); principal obstáculo contra a } \\
\text { reciclagem de esgotos para sistemas } \\
\text { hídricos. }\end{array}$ \\
\hline Vírus & $\begin{array}{c}\text { Propriedades organolépticas da água, } \\
\text { impedem a remoção de graxas e } \\
\text { óleos, tóxicos à vida aquática. }\end{array}$ \\
\hline Detergentes & Nutrientes de algas \\
\hline Fosfatos & $\begin{array}{c}\text { Propriedades organolépticas da água, } \\
\text { prejudiciais a parte da vida aquática. }\end{array}$ \\
\hline Graxas e & Aumenta a salinidade da água \\
\hline Sais & $\begin{array}{c}\text { Propriedades organolépticas da água, } \\
\text { prejudiciais a parte da vida aquática. }\end{array}$ \\
\hline Sólidos & Fonte: Manahan (2013).
\end{tabular}


Embora, vários esforços tenham sido feitos para reduzir as emissões decorrentes das atividades antrópicas, é praticamente impossível evitar contaminações ambientais (ROCHA, 2009).

Conforme Rocha et al. (2009), o saneamento básico no Brasil enfrenta imensos obstáculos de origem educacional, cultural, político, financeiro, etc. Além disso, a falta de bom senso e de informação de grande parte da população quanto aos princípios básicos de higiene, colabora para proliferação de doenças de veiculação hídrica.

\section{CONCLUSÕES}

O estudo demonstrou que, no município de Baixio$\mathrm{CE}$, o tratamento dado aos efluentes domésticos não está sendo o adequado, tanto nos parâmetros ambientais quanto nos aspectos legais. Este fato tem provocado a poluição do riacho Caio Prado, que é afluente do Rio Salgado. Outros sim, parte dos domicílios lançam seus esgotos em vias públicas, gerando o risco de contaminação das pessoas, das águas e atraindo animais e insetos causadores de doenças. Portanto, a Administração Pública municipal está amparada pela Constituição e por lei federal para propor e implementar uma solução viável aos moradores desses locais que sofrem com a falta de esgotamento correto e para dá um adequado destino ao esgoto. Aquela deve também se esforçar para aprovar o marco legal do município, visto que o projeto de lei do Código de Postura foi proposto em maio de 2013.

\section{REFERÊNCIAS BIBLIOGRÁFICAS}

ALMEIDA JR. A.F. Elemento de anatomia e fisiologia humanas. $44^{\mathrm{a}}$. ed. São Paulo: Nacional. 1985. 362 p.

ANDRADE, F.C.M. Direito Administrativo. $5^{\circ}$ Ed. São Paulo: Revista dos Tribunais, 2010.

BAIXIO. Câmara Municipal. Projeto de Lei $\mathbf{n}^{\circ}$ 008/2013. Dispõe sobre o Código de Postura do Município de Baixio, no que especifica e dá outras providências. Disponível nos arquivos da Câmara Municipal de Baixio - CE.

BRASIL. Constituição (1988). Constituição da República Federativa do Brasil. Brasília, DF: Senado Federal: Centro Gráfico, 1988.

BRASIL. Lei $\mathbf{n}^{\circ} \mathbf{1 1 . 4 4 5 / 0 7}$. Estabelece diretrizes nacionais para o saneamento básico; altera as Leis $\mathrm{n}^{\mathrm{os}} 6.766$, de 19 de dezembro de 1979, 8.036, de 11 de maio de 1990, 8.666, de 21 de junho de 1993, 8.987, de 13 de fevereiro de 1995; revoga a Lei no 6.528, de 11 de maio de 1978; e dá outras providências. Diário Oficial da República Federativa do Brasil, Brasília, 5 de janeiro de 2007.

BRASIL. Ministério da Saúde. Portaria GM no. 336 - De 19 de Fevereiro de 2002. Disponível em: <http://dtr2001.saude.gov.br/sas/PORTARIAS/Port200 2/Gm/GM-336.htm>. Acesso em: 19 jun. 2014.

BRASIL. Ministério das Cidades. Secretaria Nacional de Saneamento Ambiental - SNSA. Sistema Nacional de Informações sobre Saneamento: Diagnóstico dos
Serviços de Água e Esgotos, 2012. Brasília: SNSA/MCIDADES, 2014. 164 p.

COSTA, S.D. Estudo da viabilidade de revitalização de curso d'água em área urbana: estudo de caso no rio córrego grande em Florianópolis, Santa Catarina. Florianópolis, 2008. Dissertação (Programa de Pós Graduação em Engenharia Ambiental), Universidade Federal de Santa Catarina.

CRISPIM, D.L. Impactos ambientais no açude do bairro nova vida em Pombal-PB. Revista Brasileira de Gestão Ambiental - RGBA, Pombal-PB, v. 7, n. 3, p. 12 - 20, jul./set. 2013. Disponível em: <http://www.gvaa.com.br /revista/index.php/RBGA/article/viewFile/245-4/1956>. Acesso em: 21 jun. 2014.

EMBRAPA. Sistema brasileiro de classificação de Solos. 3 ed. rev. ampl. - Brasília, DF: Embrapa, 2013. 353 p

IBGE. Instituto Brasileiro de Geografia e Estatística. Censo Demográfico 2010. Rio de Janeiro: IBGE, 2010. Disponível em: <http://cod.ibge.gov.br/el8>. Acesso em: 22 jun. 2014.

IBGE. Instituto Brasileiro de Geografia e Estatística. Censo Demográfico 2000. Rio de Janeiro: IBGE, 2000. Disponível em: <http://www.ibge.gov.br/home/estatistica/populacao/censo2000/>. Acesso em: 22 jun. 2014.

IBGE. Instituto Brasileiro de Geografia e Estatística. Pesquisa Nacional de Saneamento Básico 2008. Rio de Janeiro: IBGE, 2010. 219 p. ISBN 978-85-2404135-8.

IPECE. Instituto de Pesquisa e Estratégia Econômica do Ceará. Perfil Básico Municipal 2013: Baixio. 2013. Disponível em: <www.ipece.ce.gov.br/ publicacoes/ perfil_ba-sico/pbm-2013/Baixio.pdf>. Acesso em: 23 Jun. 2014.

JORDÃO, E.P.; PESSOA, C.A. Tratamento de Esgotos Domésticos. 3ª ed. ABES - RJ. 1995.

KAZMIERCZAK, M.L. et al. Identificação de área de preservação florestal, através de técnicas de geoprocessamento: abordagem preliminar. In: Simpósio Brasileiro de Sensoriamento Remoto, 8., 1996, Salvador. Anais... Salvador: INPE, 1996. p. 181-185.

LEAL, I.R. et al. Ecologia e conservação da caatinga. Recife: Ed. Universitária da UFPE, 2003. 822 p.

LENZA, P. Direito Constitucional Esquematizado. $16^{\circ} \mathrm{Ed}$. São Paulo: Saraiva, 2012.

MANAHAN, S.E. Química Ambiental. Tradução Wilson de Figueiredo Jardim. Editora Bookman. 9a Edição, 2013. $944 \mathrm{p}$.

MENDONÇA, S. R.; CEBALOS, B.S. de O. Lagoa de Estabilização e Aeradas Mecanicamente: Novos Conceitos. João Pessoa, 1990.

MOTA, S. Introdução à Engenharia Ambiental. Rio de Janeiro, ABES, 1997.

PEGORARO, L.S. Projeto Tietê. São Paulo, Gráfica Estadão, s/d 357p. 